\title{
Theory of mind in dogs: is the perspective-taking task a good test?
}

\author{
William A. Roberts $\cdot$ Krista Macpherson
}

Published online: 5 August 2011

(C) Psychonomic Society, Inc. 2011

\begin{abstract}
Udell, Dorey, and Wynne (in press) have reported an experiment in which wolves, shelter dogs, and pet dogs all showed a significant preference for begging from a person who faced them (seer) over a person whose back was turned to them (blind experimenter). On tests with the blind person's eyes covered with a bucket, a book, or a camera, pet dogs showed more preference for the seer than did wolves and shelter dogs. We agree with the authors' position that most of these findings are best explained by preexperimental learning experienced by the subjects. We argue, however, that the perspective-taking task is not a good test of the domestication theory or of the theory of mind in dogs. The problem we see is that use of the perspective-taking task, combined with preexperimental learning in all the subjects, strongly biases the outcome in favor of a behavioral learning interpretation. Tasks less influenced by preexperimental training would provide less confounded tests of domestication and theory of mind.
\end{abstract}

Keywords Comparative Cognition · Dogs · Theory of mind

Udell, Dorey and Wynne (in press) have reported an initial study (Experiment 1) in which pet dogs, shelter dogs, and wolves chose to beg food from a person facing them with eyes uncovered (seer) or a person whose eyes were occluded in different ways (blind individual). Overall, pet dogs chose the seer more often than did shelter dogs and wolves. All types of subjects tested showed significant preference for the seer when the blind individual's back was turned to them, but only pet dogs tested indoors and outdoors showed a significant preference when a book covered the blind

W. A. Roberts $(\bowtie) \cdot$ K. Macpherson

Department of Psychology, University of Western Ontario,

London, ON N6A 5C2, Canada

e-mail: roberts@uwo.ca individual's eyes. None of the canine groups showed a significant preference for the seer when a camera covered the blind individual's eyes, and only pet dogs tested indoors significantly preferred the seer when a bucket covered the blind individual's eyes. In a second study (Experiment 2), dogs and wolves more readily learned to beg food from a seer with a bucket on her shoulder than from a blind individual with a bucket on her head.

These experiments were carried out to test two different but related theories. One theory is that dogs show theory of mind or an understanding that other organisms store information and act upon it. In the context of the perspective-taking procedure, the question is whether dogs understand that a person who sees them (seer) will know that they are begging for food but that a person who does not see them (blind individual) will not. The second theory is that dogs are particularly attentive and responsive to human social cues because they were domesticated over several thousand years from wolf ancestors (Hare, Brown, Williamson \& Tomasello 2002; Miklosi et al., 2003). These two theories might dovetail if it were assumed that dogs acquired theory of mind through greater sensitivity to human cues as a product of domestication. Thus, dogs might have developed the ability to "read human minds."

Both of these theories have been challenged by associative and behavioral interpretations of dogs' (and other species') behavior (Heyes, 1993; Udell, Dorey \& Wynne 2010; Udell $\&$ Wynne, 2008). Thus, apparent evidence of theory of mind might arise from learning that certain social stimuli predict particular outcomes or behaviors performed by other individuals (Gagliardi, Kirkpatrick-Steger, Thomas, Allen \& Blumberg, 1995; Heyes, 1993). The evolutionary or domestication theory of dog social responsiveness to humans has been challenged by the two-stage theory (Udell et al., 2010). This alternative interpretation of dogs' dependency 
on human cuing argues that dogs first learn to accept humans (or other species) as social companions during a critical period of development (stage 1) and, subsequently, learn to use human gestures to guide their behavior (stage 2).

Udell et al. (in press) argued that their findings can best be explained through associative learning and that they challenge predictions from the domestication and theory of-mind positions. The fact that wolves quite significantly preferred the seer when the blind individual had her back turned seems to challenge the domestication theory that wolves do not attend to human cues. The failure of some groups of canines to prefer the seer when the blind individual's eyes were covered seems to challenge the theory-of-mind prediction that dogs should recognize the blind individual as one who cannot know that they are begging. From an associative learning position, however, decline in preference for the seer in the book, camera, and bucket conditions, relative to the back-turned condition, can be explained by differential stimulus generalization. That is, an experimenter facing the dog, even with an occluder over his or her eyes, looks more like the seer than does an experimenter whose back is turned. Pet dogs may do better on these tasks (book and bucket) because they have been overtrained to approach a person with eyes visible through pre experimental occasions of begging and feeding. Canines learned to approach the seer more readily than the blind individual in Experiment 2 because learning to approach the blind individual represented a form of reversal learning based on either prior experimental training (wolves) or preexperimental training (dogs).

We generally agree with Udell et al. (in press) that their findings are best interpreted within a learning behavioral framework. However, we also argue that these experiments are not optimal tests of either domestication or theory of mind, because they stack the deck against these alternative theories. It seems to us that only an extreme interpretation of the domestication theory would lead to the prediction that wolves would not have learned some pre experimental preference for the seer. Given that these wolves were raised by humans and had participated in other behavioral experiments, they must have been fed on a number of occasions by a human facing them. Even if a wolf has no interest in human social cues, it would still surely learn that it was fed by this neutral object. The same argument can be made for shelter dogs that must have been fed by human caretakers who faced them. Thus, when tested with a human facing them versus one with his or her back turned, strong generalization to the seer and generalization decrement to the blind individual should lead to preference for the seer based on pre experimental learning.

The findings are somewhat mixed with respect to the question of theory of mind in dogs. Pet dogs did significantly prefer the seer in the book and bucket (tested indoors) conditions, but shelter dogs and wolves did not. It could be argued that pet dogs had had more opportunity to hone their theory-of-mind skills through interactions with their owners. That is, learning to understand what humans do and do not know and how to apply this knowledge may take some practice. On the other hand, pet dogs may have had a learning advantage. Although Udell et al. (in press) described Experiment 2 as a learning paradigm, it should be pointed out that Experiment 1 also involved a learning paradigm. That is, the seer fed the canine subject when approached on test trials, but the blind experimenter did not. Thus, subjects could learn to approach the seer over trials through differential reinforcement. It may be that pet dogs had an advantage over wolves and shelter dogs because they had learned to learn through previous participation in dog training programs that used differential reinforcement.

One condition used by Povinelli and Eddy (1996) with chimpanzees might have proven informative regarding the question of theory of mind. In this condition, both experimenters had their backs turned to the chimp, but one person looked over her shoulder at the subject. Thus, both experimenters appeared in a nonconventional position for begging (backs turned), but the chimp could see the eyes of one experimenter. Chimps tested surprisingly showed no preference for the person whose eyes they could see. This finding was pivotal in leading Povinelli (2000) away from a high-level (theory-of-mind) interpretation of chimpanzee understanding of human visual gaze. It suggested that simply seeing a human from the front was a cue for begging and that seeing eyes played no special role. Such an experiment with dogs might provide crucial evidence for or against theory of mind in canines.

The Udell et al. (in press) findings may be seen as evidence for theory of mind in dogs but also may be interpreted as associative learning effects. This dualinterpretation problem has plagued a number of tests of theory of mind (Heyes, 1993, 1998; but see Call \& Tomasello, 2008). In an early test of theory of mind in chimpanzees, Povinelli, Nelson and Boysen (1990) allowed a chimpanzee to see that one human observed where food was hidden (knower), whereas another human entered the room after the food was hidden and, thus, did not make this observation (guesser). When the knower and guesser pointed at different food locations, chimpanzees showed a preference for the location pointed at by the knower. Only 4 chimps were tested, and the significant results came from the average of many repeated trials. It is possible that chimps quickly learned to choose the container pointed at by the person who stayed in the room and to disregard the point of the person who later entered the room. Thus, cues based on the experimenters' behavior, and not inferences made about their knowledge, could account for these 
findings. Significant preference for the knower on the first trial of testing with a larger number of subjects would be more convincing.

With respect to canines, Cooper et al. (2003) reported first-trial data from an experiment with 15 dogs in which the Povinelli et al. (1990) procedure was replicated. Thus, dogs could see that one of three locations was baited with food (but not which location). They could also see that a human (knower) was in a position to see which location was baited. A second human then entered the room (guesser), and the knower and guesser pointed at different locations. The striking finding was that $14 / 15$ dogs (93\%) chose the location pointed at by the knower $(p<.001)$. On five further tests, the dogs' performance fell to little better than chance, but this drop in accuracy could be attributed to proactive interference. That is, dogs confused memories for the roles of the knower and guesser on the current trial with memories of the roles they had played on previous trials. Taken at face value, these findings are not easily explained as an effect of associative learning and strikingly agree with prediction from theory of mind. This experiment should be replicated. The problem of proactive interference from repeated tests might be reduced by spacing trials further apart in time (Grant, 1975, 1981) and/or by using different people as the knower and guesser on each trial.

In conclusion, although we find the Udell et al. (in press) findings interesting, we are not persuaded that they argue convincingly against either domestication or theory of mind. We see these experiments as too confounded by possible learning effects from both pre experimental and experimental sources. The perspective-taking (food-begging) task, then, may not be the best test of these theories for dogs and wolves that have experienced considerable prior interaction with humans. Other behavioral tests should be sought that better control for the effects of prior learning and, thus, are less subject to multiple interpretations.

Author Note William A. Roberts and Krista Macpherson, Department of Psychology, University of Western Ontario.

\section{References}

Call, J., \& Tomasello, M. (2008). Does the chimpanzee have a theory of mind? 30 years later. Trends in Cognitive Sciences, 12, 187-192.

Cooper, J. J., Ashton, C., Bishop, S., West, R., Mills, D. S., \& Young, R. J. (2003). Clever hounds: Social cognition in the domestic dog (Canis familiaris). Applied Animal Behaviour Science, 81, 229244.

Gagliardi, J. L., Kirkpatrick-Steger, K. K., Thomas, J., Allen, G. J., \& Blumberg, M. S. (1995). Seeing and knowing: Knowledge attribution versus stimulus control in adult humans (Homo sapiens). Journal of Comparative Psychology, 109, 107-114.

Grant, D. S. (1975). Proactive interference in pigeon short-term memory. Journal of Experimental Psychology. Animal Behavior Processes, 104, 207-220.

Grant, D. S. (1981). Intertrial interference in rat short-term memory. Journal of Experimental Psychology. Animal Behavior Processes, 7, 217-227.

Hare, B., Brown, M., Williamson, C., \& Tomasello, M. (2002). The domestication of social cognition in dogs. Science, 298, 1634 1636.

Heyes, C. M. (1993). Anecdotes, training, trapping and triangulating: Do animals attribute mental states? Animal Behaviour, 46, 177188.

Heyes, C. M. (1998). Theory of mind in nonhuman primates. The Behavioral and Brain Sciences, 21, 101-114.

Miklosi, A., Kubinyi, E., Topal, J., Gacsi, M., Viranyi, Z., \& Csanyi, V. (2003). A simple reason for a big difference: Wolves do not look back at humans, but dogs do. Current Biology, 13, 763-766.

Povinelli, D. J. (2000). Folk physics for apes. Oxford: Oxford University Press.

Povinelli, D. J., \& Eddy, T. J. (1996). What young chimpanzees know about seeing. Monographs of the Society for Research in Child Development, 61, v-191.

Povinelli, D. J., Nelson, K. E., \& Boysen, S. T. (1990). Inferences about guessing and knowing by chimpanzees (Pan troglodytes). Journal of Comparative Psychology, 104, 203-210.

Udell, M. A. R., Dorey, N. R., \& Wynne, C. D. L. (2010). What did domestication do to dogs? A new account of dogs' sensitivity to human actions. Biological Reviews, 85, 327-345.

Udell, M. A. R., Dorey, N. R., \& Wynne, C. D. L. (in press). Can your dog read your mind? Understanding the causes of canine perspective taking. Learning \& Behavior.

Udell, M. A. R., \& Wynne, C. D. L. (2008). A review of domestic dogs' (Canis familiaris) human-like behaviors: Or why behavior analysts should stop worrying and love their dogs. Journal of the Experimental Analysis of Behavior, 89, 247-261. 